\title{
Reproduction and Horticultural Performance of Transgenic Ethylene-insensitive Petunias
}

\author{
Erika K. Gubrium, Donna J. Clevenger, David G. Clark, ${ }^{1}$ James E. Barrett, and Terril A. Nell \\ Department of Environmental Horticulture, University of Florida, Gainesville, FL 32611-0670
}

\begin{abstract}
AdDitional INDEX wORDs. Petunia $\times$ hybrida, ethylene sensitivity, flower senescence, fruit ripening, seed germination, adventitious root formation

Abstract. A series of experiments on ethylene-insensitive (EI) petunia plants (Petunia $\times$ hybrida Hort. Vilm.-Andr.) generated in two genetic backgrounds were conducted to determine the involvement of ethylene in horticultural performance. Experiments examined various aspects of horticultural performance: days to flower, flower senescence after pollination and without pollination, fruit set and ripening, and adventitious root formation on vegetative stem cuttings. The development of EI plants was altered in several ways. Time from seed sowing to first flower anthesis was decreased by a week for EI plants grown at $26 / 21{ }^{\circ} \mathrm{C}$. Flower senescence in nonpollinated and self-pollinated flowers was delayed in all EI plants compared to wild-type plants. Fruit set percentage on EI plants was slightly lower than on wildtype plants and fruit ripening on EI plants was delayed by up to 7 days. EI plants produced fewer commercially acceptable rooted cuttings than wild-type plants. There was a basic difference in the horticultural performance of the two EI lines examined due to a difference in the genetic backgrounds used to generate the lines. EI plants displayed better horticultural performance when grown with day/night temperatures of $26 / 21{ }^{\circ} \mathrm{C}$ than $30 / 24{ }^{\circ} \mathrm{C}$. These results suggest that tissuespecific ethylene insensitivity as well as careful consideration of the genetic background used in transformation procedures and growth conditions of $e t r 1-1$ plants will be required to produce commercially viable transgenic floriculture crops. EI petunias provide an ideal model system for studying the role of ethylene in regulating various aspects of plant reproduction.
\end{abstract}

The gaseous hormone ethylene is well known for its involvement in flower and leaf senescence responses and fruit ripening events common to many popular floricultural and vegetable crops (Abeles et al., 1992). This senescence response to ethylene has a direct influence on the commercial postharvest longevity of many crops.

Because of its well-documented and consistent flower senescence response to ethylene, petunia (Petunia $\times$ hybrida) has proven to be an ideal model system for studying the effects of ethylene on flower senescence. When treated with $1 \mathrm{~mL} \cdot \mathrm{L}^{-1}$ ethylene for $16 \mathrm{~h}$, 'Mitchell Diploid' petunia flowers senesce and wilt in 24 to $36 \mathrm{~h}$ (Wilkinson et al., 1997). Petunia flowers display a rapid increase in ethylene production within $2 \mathrm{~h}$ of pollination, followed by the first signs of flower senescence within $24 \mathrm{~h}$ (Hoekstra and Weges, 1986). Nonpollinated petunia flowers display a rapid increase of ethylene production by $6 \mathrm{~d}$ after anthesis and peak by $9 \mathrm{~d}$ after anthesis (Whitehead et al., 1984). Once ethylene production reaches a peak, petunia flowers begin to display the symptoms of flower senescence, including flower wilting and discoloration (Whitehead et al., 1984). Therefore, ethylene has an effect on the longevity of both pollinated and nonpollinated petunia flowers. Since petunias are an important floricultural commodity (USDA, 1997), the ability to control ethylene responses through the use of genetic engineering could allow for extended petunia flower life. Although of potential commercial interest in the floriculture industry, the plants must function normally at each stage of development to be fully marketable.

Received for publication 12 July 1999. Accepted for publication 7 Feb. 2000. Florida Agricultural Experiment Station journal series R-06989. This research was funded by grants from the Fred C. Gloeckner Foundation, Inc., the Florida Nursery Growers Association, and a University of Florida Research Project Enhancement Award. The cost of publishing this paper was defrayed in part by the payment of page charges. Under postal regulations, this paper therefore must be hereby marked advertisement solely to indicate this fact.

${ }^{1}$ Corresponding author.
Major breakthroughs in the control of ethylene-induced responses have been made by identifying mutant genes in Arabidopsis thaliana (L.) Heynh. that confer ethylene insensitivity (Kende, 1993). Researchers identified a mutant gene in Arabidopsis, etr 1-1, which acted in a dominant fashion to confer ethylene insensitivity (Chang et al., 1993). Wilkinson et al. (1997) transformed the heterologous plant species Lycopersicon esculentum Mill. (tomato), Petunia $\times$ hybrida, and Nicotiana tabacum L. (tobacco) with the Arabidopsis etrl-1 gene and successfully conferred ethylene insensitivity. An ethylene-insensitive phenotype of delayed flower senescence after pollination and after exogenous ethylene treatment was observed in petunia. In this work, the inbred petunia cultivar Mitchell Diploid ('MD') was transformed with a genetic construct containing the etrl-1 transgene linked to a cauliflower mosaic virus $35 \mathrm{~S}$ promoter (CaMV35S). Use of the CaMV35S promoter to drive expression of the etrl-1 transgene in the transformed plants allowed for examination of plants with constitutive insensitivity to ethylene (Wilkinson et al., 1997). Arabidopsis mutants containing the etr 1-1 mutation have been characterized as being defective in several developmental processes. In addition to displaying increased flower petal longevity, mutant plants display a decreased rate of seed germination and delayed flower initiation (Bleecker et al., 1988). These results suggest that plants engineered to be constitutively unresponsive to ethylene could have potential commercial limitations.

The present study characterizes a range of effects of the etrl1 transgene on the gross morphology of transformed petunia plants. This characterization involves an examination of the growth and development (horticultural performance) of ethylene-insensitive transgenic plants generated by Wilkinson et al. (1997) and an additional transgenic line generated using a similar transgene in the highly inbred 'V26' background. Horticultural performance of ethylene-insensitive transgenic petunia plants was evaluated in various areas that are closely related to crop production and pertinent to the commercial viability of the plants. 
Flower timing was observed to determine if crop timing would be a constraint; flower senescence was observed to determine if ethylene-insensitive pollinated and nonpollinated flowers displayed increased longevity; and fruit production, maturation, and seed germination were studied to determine sexual reproductive ability. Adventitious root formation of the plants was also studied to confirm the previous observations of decreased rooting performance of vegetative stem cuttings of ethylene-insensitive petunia plants during vegetative propagation (Clark et al., 1999). Conclusions drawn from horticultural performance evaluations reinforce the involvement of ethylene in whole-plant processes and illustrate potential commercial advantages and limitations of this technology.

\section{Materials and Methods}

Plant materials, transformation, and Cultural CONDiTIONS. Wild-type inbred Petunia $\times$ hybrida 'Mitchell Diploid' ('MD') and transgenic ethylene-insensitive (EI) 'MD' plants (line 44568; Wilkinson et al., 1997) were examined. $\mathrm{T}_{1}$ generation plants in the 'MD' genetic background that displayed an ethylene-insensitive phenotype were self-pollinated, generating heterozygous $T_{2}$ generation plants. $T_{2}$ plants were used in all subsequent horticultural experiments. Plants from the highly inbred cultivar 'V26' were genetically transformed at the University of Florida in Fall 1997 with a similar genetic construct used by Wilkinson et al. (1997), according to the method of Jorgensen et al. (1996). One original transgenic plant in the 'V26' background displayed an ethylene-insensitive phenotype (C96-3-30) and was self-pollinated to produce $T_{1}$ generation plants. $T_{1}$ plants showing the EI phenotype were used in all subsequent horticultural performance experiments.

Two separate crops of plants in 'MD' and 'V26' genetic backgrounds were grown to investigate time to flower anthesis, pollination-induced and natural flower senescence, and fruit set in wild-type and EI plants. For the first crop, 53 'MD' plants, 22 44568 plants, 25 'V26' plants, and 41 C96-3-30 plants were arranged in a completely randomized design and were grown at 12-h days of $30^{\circ} \mathrm{C}$ with average irradiance of $1515 \mu \mathrm{mol} \cdot \mathrm{m}^{-2} \cdot \mathrm{s}^{-1}$ and 12 -h nights of $24^{\circ} \mathrm{C}$. For the second crop, 29 'MD' plants, 5444568 plants, 18 'V26' plants and 14 C96-3-30 plants were arranged in a completely randomized design and were grown with at 12-h days of $26^{\circ} \mathrm{C}$ and an average irradiance of $835 \mu \mathrm{mol} \cdot \mathrm{m}^{-2} \cdot \mathrm{s}^{-1}$ and $12-\mathrm{h}$ nights of $21^{\circ} \mathrm{C}$. Both crops were grown in a commercial potting medium (Fafard Mix No. 2; Conrad Fafard, Inc., Apopka, Fla.) in 1.5-L pots. Plants were fertilized daily with $\mathrm{N}$ at $150 \mathrm{mg} \cdot \mathrm{L}^{-1}$ from a $15 \mathrm{~N}-7 \mathrm{P}-14.1 \mathrm{~K}$ water soluble fertilizer (Peter's Fertilizer Products, The Scotts Co., Marysville, Ohio). Data for experiments examining fruit ripening and adventitious root formation were recorded on the crop grown in a completely randomized design at 12-h days of $26^{\circ} \mathrm{C}$ and 12-h nights of $21^{\circ} \mathrm{C}$ as described previously.

Time TO FLOWER ANTHESIS. To determine if differences in time to flower anthesis existed between EI and wild-type petunia plants, the number of days from time of seed sowing to anthesis of the first flower was determined for each plant in the two crops of wild-type and EI plants (see above). Means and SEs for time from seed sowing to first flower anthesis were calculated separately for each crop of wild-type 'MD' and 'V26' plants and EI plants in 'MD' and 'V26' backgrounds, using the means procedure of SAS (version 6.12; SAS Institute, Inc., Cary, N.C.).

Flower SENESCENCE. Pollination-induced flower senescence was assessed in two crops of plants (see above) to determine differences in flower longevity between EI and wild-type petunia plants. Plants were grown to flowering, then were tested for flower senescence after self-pollination. All flowers were selfpollinated $1 \mathrm{~d}$ after anthesis and were tagged with the date. Fifty 'MD' flowers, 139 EI 44568 flowers, 20 'V26' flowers and 32 EI C96-3-30 flowers from the crop of plants grown at day/night temperatures of $30 / 24{ }^{\circ} \mathrm{C}$ were pollinated. In total, 56 'MD' flowers, 121 EI 44568 flowers, 30 'V26' flowers, and 18 EI C963-30 flowers from the crop of plants grown at day/night temperatures of $26 / 21^{\circ} \mathrm{C}$ were pollinated. The date of the first sign of petal wilting was subsequently recorded for each and the number of days from flower pollination to flower senescence calculated.

An additional flower senescence assay without pollination was conducted on the same crops of plants to determine if differences exist between EI transgenic and wild-type plants for longevity of nonpollinated flowers. Flowers on each transgenic and wild-type plant were tagged on the day of flower anthesis and again on the day of petal wilting, and the number of days from flower opening to flower senescence was recorded. In total, 23 'MD' flowers, 5644568 flowers, 13 'V26' flowers, and 11 C963-30 flowers were examined from the crop of plants grown at 30/ $24{ }^{\circ} \mathrm{C}$. From the crop of plants grown at $26 / 21{ }^{\circ} \mathrm{C}, 27$ 'MD' flowers, 2344568 flowers, 17 'V26' flowers, and 13 C96-3-30 flowers were examined. Means and SEs were calculated separately for plant lines within each crop for the number of days for flowers to wilt with and without pollination, using the means procedure of SAS.

Fruit SeT AND maturation. The number of fruit (capsules) produced from flowers pollinated in the flower senescence assay was counted on plants grown in greenhouses set at day/night temperatures of $30 / 24{ }^{\circ} \mathrm{C}$ or $26 / 21^{\circ} \mathrm{C}$ to determine differences between EI and wild-type petunia flowers in their ability to set fruit. Fruit set was recorded $20 \mathrm{~d}$ after pollination. Fruit ripening was only examined on the flowers from the crop grown at 26/21 ${ }^{\circ} \mathrm{C}$ (see above) because flowers on EI plants grown at $30 / 24{ }^{\circ} \mathrm{C}$ rarely set sizeable fruit ( $\leq 5 \mathrm{~mm}$ in diameter, as opposed to wildtype fruit, which had a diameter of $\approx 10 \mathrm{~mm}$ ). A fruit ripening date was recorded for 50 'MD' fruit, 14144568 fruit, 20 'V26' fruit, and 44 C96-3-30 fruit after self-pollination to determine the difference between EI and wild-type. The date of fruit ripening was determined to be the date when fruit were completely brown in color, and had just reached a point of dehiscence. The percentage of fruit set per total number of self-pollinations was calculated separately for each line of EI and wild-type plants within each crop. Means and SEs for the number of days to fruit ripening were calculated for each line, using the means procedure of SAS.

Adventitious rooting. To determine if differences existed between EI and wild-type stem cuttings for their ability to produce adventitious roots, two crops of plants were grown at 26/ $21{ }^{\circ} \mathrm{C}$ (described above). Because 'MD' plants generally produced more stem cuttings than 'V26' plants, 'MD' cuttings represented a larger portion of the sample population. In total, 131 wild-type 'MD' cuttings, 109 EI 44568 cuttings, 29 wild-type 'V26' cuttings, and 19 EI C96-3-30 cuttings were examined in the first crop. In the second crop, 114 wild-type 'MD' cuttings, 416 EI 44568 cuttings, 111 wild-type 'V26' cuttings, and 66 EI C963-30 cuttings were examined. For both crops, 1.6-cm vegetative cuttings, each bearing three leaves were taken from 10 -week-old petunia plants and were placed directly in four-cell packs (each cell $=80 \mathrm{~mL}$ ), with one inch of the basal portion of the cutting inserted into a medium of 2 perlite : 1 commercial potting soil (v/v) (Fafard 
2B). Cuttings were placed under intermittent mist with 12-h days of $25^{\circ} \mathrm{C}$ with an average light intensity of $314 \mu \mathrm{mol} \cdot \mathrm{m}^{-2} \cdot \mathrm{s}^{-1}$ and $12-\mathrm{h}$ nights of $22^{\circ} \mathrm{C}$. Cuttings were arranged in randomized complete blocks assigned according to genotype. The mist operated during the 12-h days for $5 \mathrm{~s}$ every $20 \mathrm{~min}$ the first week and for 5 s every 30 min the following week. After 2 weeks, cuttings were compared to a set of standard cuttings, each of which represented a score of 0 to 5 based on adventitious root formation: $0=$ no adventitious roots, $1=$ one adventitious root, $2=$ two to four adventitious roots, 3 = five to 10 adventitious roots, $4=11$ to 18 adventitious roots, and $5=$ more than 18 adventitious roots. Cuttings were evaluated as commercially acceptable if they produced five or more adventitious roots, thus assigned a rating $\geq 3$. The number of commercially acceptable wild-type and EI cuttings representing each genetic background was calculated as a percentage of the total number of cuttings placed under mist. Results from both crops were statistically the same and were therefore combined to increase the sample size.

\section{Results and Discussion}

Flowering. 'MD', 'V26', and C96-3-30 plants grown at 30/ $24{ }^{\circ} \mathrm{C}$ flowered faster than the same genotypes grown at $26 / 21^{\circ} \mathrm{C}$ (Table 1). When grown at $30 / 24^{\circ} \mathrm{C}$, wild-type and EI plants in the 'MD' genetic background took about the same amount of time to flower, while C96-3-30 plants flowered faster than wild-type 'V26' plants. EI plants in the 'MD' and 'V26' genetic backgrounds both flowered faster than wild-type 'MD' and 'V26' plants, respectively, when grown at $26 / 21^{\circ} \mathrm{C}$ (Table 1). These results suggest that different genetic backgrounds may respond differently to insertion of the etr $l-1$ transgene. They also suggest that the temperature under which these plants are grown has some bearing on their expression of an EI phenotype. It is also possible that etr $1-1$ was inserted into the genome of ' $\mathrm{V} 26$ ' in such a way that other genes involved in flowering were affected, whereas the

Table 1. Mean number of days ( \pm SE) from seed sowing to first flower anthesis. Flowers were examined from wild-type 'MD' and 'V26' and ethylene insensitive plants from the genotypes 44568 and C963-30 grown at $30 / 24{ }^{\circ} \mathrm{C}$ or $26 / 21{ }^{\circ} \mathrm{C}$.

\begin{tabular}{lcc}
\hline \hline & \multicolumn{2}{c}{ Days to anthesis } \\
\cline { 2 - 3 } & \multicolumn{2}{c}{ Temp $\left({ }^{\circ} \mathrm{C}\right)$} \\
\cline { 2 - 3 } Genotype & $30 / 24$ & $26 / 21$ \\
\hline MD & $76.5 \pm 1.56$ & $91.3 \pm 1.58$ \\
44568 & $77.4 \pm 1.52$ & $80.0 \pm 2.44$ \\
V26 & $80.9 \pm 1.87$ & $88.8 \pm 2.20$ \\
C96-3-30 & $72.6 \pm 0.99$ & $81.3 \pm 1.60$ \\
\hline
\end{tabular}

placement of etrl-1 within the 'MD' genome had no effect. Ethylene is not typically associated with flower induction processes, but is known to induce flowering in a few species, such as Lithci chinensis Sonn. (lychee) (Chen and Ku, 1988), Plumbago indica L. (plumbago) (Nitsch and Nitsch, 1969), Mangifera indica L. (mango) (Chacko et al., 1974), and Cichorium intybus var. Foliosus (Belgian endive) (De Proft et al., 1986). The ethylene-releasing compound, ethephon, is commonly used to induce flowering of horticultural crops such as Ananas comosus Merr. (pineapple) and mango (Abeles et al., 1992). EI plants grown under typical production conditions $\left(26 / 21^{\circ} \mathrm{C}\right)$ flower a week earlier than wild-type plants, which suggests that differences caused by the introduction of the etr $1-1$ transgene into petunia plants could be a beneficial aspect of their horticultural performance. Additional transgenic etr $1-1$ lines should be placed into other genetic backgrounds, however, to better gauge the significance of ethylene in petunia flowering.

Flower SENESCENCE. Wild-type flowers consistently lasted from 2 to $3 \mathrm{~d}$ after pollination in both warm and cool greenhouse conditions. Flowers from EI plants in both genetic backgrounds showed delayed senescence after pollination when compared with flowers on wild-type plants (Table 2). The EI phenotype was most pronounced when EI plants were grown at $26 / 21^{\circ} \mathrm{C}$ : selfpollinated flowers from 44568 plants lasted eight times longer than wild-type 'MD' plants and flowers from C96-3-30 plants lasted three times longer than wild-type 'V26' plants (Table 2). When grown at $30 / 24^{\circ} \mathrm{C}$, self-pollinated flowers from EI 44568 plants lasted slightly more than twice as long as wild-type 'MD' flowers and flowers from C96-3-30 plants lasted slightly less than twice as long as wild-type 'V26' flowers (Table 2). Wilkinson et al. (1997) reported that flowers from EI plants in the 'MD' background lasted more than twice as long as wild-type 'MD' flowers following self-pollination and after treatment with exogenous ethylene. Our flower senescence assays following pollination showed an even more profound difference between wildtype and EI plants in flower longevity when plants were grown at $26 / 21^{\circ} \mathrm{C}$. While the delayed flower senescence phenotype was much more pronounced on EI plants grown at $26 / 21^{\circ} \mathrm{C}$ than on EI plants grown at $30 / 24{ }^{\circ} \mathrm{C}$, flower longevity remained consistent for wild-type plants regardless of greenhouse conditions (Table 2); suggesting that plants containing the etrl-1 transgene will perform differently under different cultural conditions. Other environmental factors, in addition to ethylene, may also come into play when determining the flower senescence phenotype of EI plants at higher temperatures. EI plants from the C96-3-30 lines displayed a much weaker delayed flower senescence phenotype than EI plants from the 44568 lines, which suggests that the C96-3-30 line may not be as ethylene insensitive as the 44568 line. Production of plants in diverse genetic lines will, therefore,

Table 2. Mean number of days ( \pm SE) to flower senescence after self-pollination or without pollination. Wild-type 'MD' and 'V26' and ethyleneinsensitive 44568 and C96-3-30 flowers were examined on plants grown at $30 / 24{ }^{\circ} \mathrm{C}$ or $26 / 21{ }^{\circ} \mathrm{C}$.

\begin{tabular}{|c|c|c|c|c|}
\hline \multirow{3}{*}{ Genotype } & \multicolumn{4}{|c|}{ Days to senescence } \\
\hline & \multicolumn{2}{|c|}{ Pollinated } & \multicolumn{2}{|c|}{ Nonpollinated } \\
\hline & \multicolumn{4}{|c|}{ Temp $\left({ }^{\circ} \mathrm{C}\right)$} \\
\hline & $30 / 24$ & $26 / 21$ & $30 / 24$ & $26 / 21$ \\
\hline$\overline{\mathrm{MD}}$ & $2.1 \pm 0.44$ & $2.1 \pm 0.10$ & $6.0 \pm 0.25$ & $6.7 \pm 0.21$ \\
\hline 44568 & $5.7 \pm 0.11$ & $16.9 \pm 0.51$ & $7.9 \pm 0.40$ & $16.6 \pm 0.62$ \\
\hline V26 & $2.3 \pm 0.07$ & $2.6 \pm 0.17$ & $5.1 \pm 0.25$ & $7.5 \pm 0.45$ \\
\hline C96-3-30 & $4.2 \pm 0.22$ & $7.3 \pm 0.38$ & $6.5 \pm 0.99$ & $10.3 \pm 0.26$ \\
\hline
\end{tabular}


Table 3. Percent fruit set per flower pollination on plants grown at 30/24 ${ }^{\circ} \mathrm{C}$ or $26 / 21^{\circ} \mathrm{C}$ and mean number of days ( \pm SE) from self-pollination to ripening of wild-type 'MD' and 'V26' and ethylene-insensitive 44568 and C96-3-30 petunia fruits on plants grown at $26 / 21^{\circ} \mathrm{C}$.

\begin{tabular}{lccc}
\hline & \multicolumn{2}{c}{ Fruit set $(\%)$} & \\
\cline { 2 - 3 } & \multicolumn{2}{c}{ Temp $\left({ }^{\circ} \mathrm{C}\right)$} & \\
\cline { 2 - 3 } Genotype & $30 / 24$ & $26 / 21$ & Days to fruit ripening \\
\hline MD & 90 & 94 & $24.7 \pm 0.33$ \\
44568 & 78 & 80 & $31.2 \pm 0.21$ \\
V26 & 42 & 78 & $27.7 \pm 0.33$ \\
C96-3-30 & 38 & & $34.2 \pm 0.30$
\end{tabular}

Table 4. Percent commercially acceptable cuttings (five or more adventitious roots produced/cutting). Data were taken on cuttings from wild-type 'MD' and 'V26' plants and ethylene-insensitive 44568 and C96-3-30 plants 2 weeks after the onset of propagation.

\begin{tabular}{lc}
\hline \hline Genotype & $\begin{array}{c}\text { Commercially } \\
\text { acceptable }(\%)\end{array}$ \\
\hline MD & 92.7 \\
44568 & 27.5 \\
V26 & 90.0 \\
C96-3-30 & 16.5 \\
\hline
\end{tabular}

be warranted to determine the degree of ethylene insensitivity that can be achieved and how much it depends on diversity of germplasm used.

In addition to examining the longevity of EI flowers following self-pollination, we also determined whether nonpollinated flowers from EI plants would senesce slower than wild-type flowers. Flowers from all EI plants senesced slower than wild-type flowers at both $30 / 24{ }^{\circ} \mathrm{C}$ and $26 / 21{ }^{\circ} \mathrm{C}$ (Table 2). Delays in natural senescence of EI flowers were not as distinct as delays in pollinationinduced senescence. Similar to the flower pollination assay, all EI flowers on plants grown at $26 / 21^{\circ} \mathrm{C}$ lasted longer than EI flowers from plants grown at $30 / 24{ }^{\circ} \mathrm{C}$. Flowers from 44568 plants grown at $26 / 21^{\circ} \mathrm{C}$ lasted more than twice as long as flowers from wild-type 'MD' plants; flowers from C96-3-30 plants lasted $\approx 30 \%$ longer than wild-type 'V26' flowers (Table 2). Results from the flower assays without pollination serve to underscore the effect of greenhouse temperature conditions on the senescence of EI flowers, again suggesting that ethylene-regulated processes are not the only physiological factors influencing flower senescence, especially under adverse conditions. Flowers from C96-3-30 plants did not have as pronounced a delay in senescence as flowers from 44568 plants. This lends further support to evidence that the C96-3-30 line maintained some residual sensitivity to ethylene.

SEED PRODUCTION AND FRUIT MATURATION. Percentage of fruit set after self-pollination of EI plants in both 'MD' and 'V26' backgrounds was variable under different temperature conditions. In total, $81 \%$ of self-pollinated EI 44568 and $78 \%$ of EI C96-3-30 flowers set fruit at $26 / 21{ }^{\circ} \mathrm{C}$, compared to $94 \%$ and $80 \%$ for wildtype 'MD' and 'V26,' respectively (Table 3 ). Only $42 \%$ of selfpollinated EI 44568 and 38\% of EI C96-3-30 flowers set fruit at 30/ $24{ }^{\circ} \mathrm{C}$, compared to $90 \%$ and $78 \%$ fruit set for wild-type 'MD' and 'V26,' respectively (Table 3).

Involvement of ethylene in fruit ripening has been studied extensively. However, ethylene is not widely associated with the process of fruit induction or fruit set. This aspect of reproductive development partly determines the amount of seed that the crop will yield. The seed yield of a commercially produced crop must be relatively high for the crop to be successful. EI plants grown at 30/ $24^{\circ} \mathrm{C}$ did not perform as well in both fruit set and flower longevity assays as EI plants grown at $26 / 21^{\circ} \mathrm{C}$, and we also observed that EI fruit displayed abnormal development at $30 / 24{ }^{\circ} \mathrm{C}$ (data not presented). Wild-type plants, however, performed in a similar manner at both temperature regimes; suggesting that ethylene may be involved in plant adaptations to heat stress, allowing plants to reproduce more efficiently under extreme temperature conditions. Because we observed decreased fruit set and abnormal fruit development on plants grown at higher temperatures, further experiments need to be conducted under adverse conditions to explore the type of influence that ethylene may have on the developmental processes leading to fruit set as well as on the processes leading to fruit maturity.

EI 44568 and EI C96-3-30 fruit took $\approx 6$ to $7 \mathrm{~d}$ longer to attain a fully ripened state than wild-type 'MD' and 'V26' fruit (Table 3). The involvement of ethylene in fruit ripening has been studied more than any other aspect of ethylene science, and tomato plants have been one of the primary model systems used to study the fruit ripening process (Abeles et al., 1992). The ethylene-insensitive, 'Never-ripe' tomato displays fruit that do not reach full maturity (Lanahan et al., 1994; Wilkinson et al., 1995). Fruit ripening is delayed on EI petunias. However, these fruits eventually reach full maturity. The manner in which a petunia fruit and a tomato fruit ripen are quite different; petunia fruit ripen by a process of dry down and dehiscence, while fleshy tomato fruit ripen through a process of softening. It is therefore logical that ethylene insensitivity inhibits fruit ripening in different ways in each type of fruit. However, results showing altered fruit ripening in EI petunia reinforces previous evidence showing that ethylene is integrally involved in the process of fruit development and maturity in many plant species (Abeles et al., 1992). Along with a lowered fruit set and delayed fruit ripening, we also observed that a much lower percentage of seeds from EI plants germinated than did seeds from wild-type plants (data not presented). Bleecker et al. (1988) reported that ethylene-insensitive Arabidopsis seeds containing the etrl-1 mutation displayed markedly reduced levels of germination and treatment with gibberellic acid $\left(\mathrm{GA}_{3}\right)$ was effective in overcoming low levels of seed germination. While we have observed that treatment with $\mathrm{GA}_{3}$ is partially effective in increasing germination levels of seeds produced on EI plants, germination rates of seeds produced on EI petunia plants are still lower than that of seeds produced on wild-type plants (data not presented). Since the etrl-1 mutation is dominant to wild-type, it is likely that EI plants will have to be used as pollen parents in $\mathrm{F}_{1}$ hybrid seed production to allow for adequate fruit development, seed set, and subsequent seed germination. Experiments to further examine performance of pollen from EI plants will determine whether this will be an adequate approach. Experiments involving reciprocal crosses between inbred EI and wild-type plants should also be conducted to determine the appropriate breeding strategy that will maximize seed production, fruit ripening, and germination efficiency.

Adventitious Rooting. Rooted stem cuttings were deemed to be commercially acceptable if they produced five or more adventitious roots per cutting. Wild-type 'MD' and wild-type 'V26' plants produced $92.7 \%$ and $90.0 \%$ commercially viable cuttings, respectively (Table 4). EI 'MD' and 'V26' plants produced significantly fewer commercially acceptable cuttings than wild-type plants, with EI plants from the 44568 line producing $27.5 \%$ commercially acceptable cuttings and EI plants from the C96-3-30 line producing only $16.5 \%$ commercially acceptable cuttings (Table 4 ).Zimmerman and Hitchcock (1933) first reported that ethylene was involved in the 
promotion of adventitious root formation by exposing 27 different plant species to relatively high concentrations of ethylene and then comprehensively characterizing the physiological effects of ethylene on plant growth and development. Clark et al. (1999) reported that transgenic etr $1-1$ petunia and tomato cuttings produced significantly fewer adventitious roots than wild-type plants, suggesting that the perception of ethylene was critical to various root responses to environmental stimuli. Results from the present study were similar to those observed by Clark et al. (1999). Ethylene insensitivity severely inhibited adventitious root formation in both petunia cultivars tested. The difficulty in producing commercially acceptable cuttings on EI petunia plants suggests that this may be a problem in other floriculture crops undergoing transformation with etr1-1. Vegetative propagation is a means of plant reproduction for many floricultural crops. Therefore, the inability of EI cuttings to successfully produce adventitious roots poses a serious commercial limitation to the grower's ability to multiply the crop.

Ethylene insensitivity affects several areas of plant development in the transgenic etr $1-1$ petunia plants examined in this study. The ability to create ethylene-insensitive plants with delayed flower senescence has great commercial potential in the floriculture industry. Since plants have evolved elaborate hormone perception systems, it is logical to hypothesize that constitutive suppression of the perception of any hormone would be detrimental to some stage(s) of whole plant development. Not only do transgenic etr $1-1$ plants have longer lasting flowers, but fruit development is delayed, seed germination is inhibited, and adventitious root formation is significantly decreased. In using the etrl-1 transgene driven by the constitutively expressed CaMV35S promoter, it is clear that developmental processes other than flower senescence are altered. Use of tissue-specific promoters to drive expression of the etr $1-1$ transgene may allow a strong EI phenotype to be expressed in only desired parts of the plant, resulting in development of petunia plants with longer lasting flowers, but with otherwise unaltered horticultural performance. In addition, the basic differences in horticultural performance between the wild-type 'MD' and 'V26' lines and the transgenic lines generated from each suggest that the choice of a genetic background for use in producing transgenic etr $1-1$ lines can greatly affect their resulting levels of ethylene sensitivity and horticultural performance. Differences between EI and wild-type plants grown at various temperatures suggest that growing conditions are an important consideration for successful production of etr $1-1$ plants. Regardless of whether impaired development is avoidable, the constitutive ethylene-insensitive petunias used in these experiments provide excellent model systems with which to examine the role of ethylene in regulating whole-plant processes such as flower longevity, fruit ripening, seed germination, and adventitious root formation.

\section{Literature Cited}

Abeles, F.B., P.W. Morgan, and M.E. Saltveit. 1992. Ethylene in plant biology. Academic Press, San Diego.

Bleecker, A.B., M.A. Estelle, C. Sommerville, and H. Kende. 1988. Insensitivity to ethylene conferred by a dominant mutation in Arabidopsis thaliana. Science 241:1086-1089.

Chacko, E.K., R.R. Kohli, and G.W. Randhawa. 1974. Investigations on the use of (2-chloroethyl) phosphonic acid (ethephon, CEPA) for the control of biennial bearing in mango. Sci. Hort. 2:389-398.

Chang, C., S.F. Kwok, A.B. Bleecker, and E.M. Meyerowitz. 1993. Arabidopsis ethylene-response gene ETRI: Similarity of product to two-component regulators. Science 262:539-544.

Chen, W-S and M-L Ku. 1988. Ethephon and kinetin reduce shoot length and increase flower bud formation in lychee. HortScience 23:1078.

Clark, D.G., E.K. Gubrium, J.E. Barrett, T.A. Nell, and H.J. Klee. 1999. Root formation in ethylene-insensitive plants. Plant Physiol. 121:5359.

De Proft, M., J. De Greef, K. Van Nerum, and G. Goffins. 1986. Ethylene in the production of belgian endive. HortScience 21:11321133.

Hoekstra, F.A. and R. Weges. 1986. Lack of control by early pistillate ethylene of the accelerated wilting of Petunia hybrida flowers. Plant Physiol. 80:403-408.

Jorgensen, R.A., P.D. Cluster, J. English, Q. Que, and C.A. Napoli. 1996. Chalcone synthase cosuppression phenotypes in petunia flowers: Comparison of sense vs. antisense constructs and single-copy vs. complex T-DNA sequences. Plant Mol. Biol. 31:957-973.

Kende, H. 1993. Ethylene biosynthesis. Annu. Rev. Plant Physiol. Plant. Mol. Biol. 44:283-307.

Lanahan, M.B., H-C. Yen, J.J. Giovannoni, and H.J. Klee. 1994. The 'Never-ripe' mutation blocks ethylene perception in tomato. Plant Cell 6:521-530.

Nitsch, C. and J.P. Nitsch. 1969. Floral induction in a short-day plant, Plumbago indica L., by 2-chloroethanephosphonic acid. Plant Physiol. 44:1747-1748.

U.S. Department of Agriculture. 1997. Annual report for floriculture crops. USDA, Washington D.C.

Whitehead, C.S., A.H. Halevy, and M.S. Reid. 1984. Roles of ethylene and 1-aminocyclopropane-1-carboxylic acid in pollination and woundinduced senescence of Petunia hybrida flowers. Physiol. Plant. 61:643648.

Wilkinson, J.Q., M.B. Lanahan, D.G. Clark, A.B. Bleecker, C. Chang, E.M. Meyerowitz, and H.J. Klee. 1997. A dominant mutant receptor from Arabidopsis confers ethylene insensitivity in heterologous plants. Nature Biotechnol. 15:444-447.

Wilkinson, J.Q., M.B. Lanahan, H-C. Yen, J.J. Giovannoni, H.J. Klee. 1995. An ethylene-inducible component of signal transduction encoded by 'Never-ripe'. Science 270:1807-1809.

Zimmerman, P.W. and A.E. Hitchcock. 1933. Initiation and stimulation of adventitious roots caused by unsaturated hydrocarbon gases. Contrib. Boyce Thompson Inst. 5:351-361. 